\title{
O DEVIR COMO INTERSECÇÃO DOS CONCEITOS DE ARTE E DIREITO
}

\author{
Thiago Florentino da Silva Lima* \\ Sandra Helena da Conceição Campos***
}

Resumo: Este artigo apresenta como foco de análise a distinção entre o entendimento dos conceitos de arte e de direito que podem ser considerados como conceitos abertos ou fechados. O objetivo deste artigo é expor a relação entre arte e direito através do conceito grego de devir. Inserindo essa conjunção em uma dinâmica de movimento e continuidade. Revelando que a simplificação do fato pela linguagem jurídica é vinculada à necessidade da retórica, consequentemente em conformidade com a Antropologia Filosófica Alemã.

Palavras-chave: Direito; Arte; Devir; Instituições; Ordem

\section{THE BECOMING AS INTERSECTION OF THE CONCEPTS OF ART AND LAW}

Abstract: This article presents as focus of analysis the distinction between understanding the concepts of art and law that can be considered as open or closed concepts. The objective of this paper is to expose the relation between art and law through the Greek concept of becoming. Inserting this conjunction in a dynamic of movement and continuity. Revealing that the simplification of the fact by legal language is linked to the need for rhetoric, consequently in compliance with the German Philosophical Anthropology.

Keywords: Law; Art; Becoming; Institutions; Order

\section{INTRODUÇÃO}

Este artigo traz o enfoque analítico na diferenciação entre a compreensão dos conceitos de direito e arte enquanto conceitos abertos ou fechados. De modo que esta diferenciação conceitual acaba por revelar a vinculação entre estes por meio do conceito grego de devir. A importância deste estudo incide em demonstrar que o conceito de devir pode ser tomado como base para se justificar a adoção dos conceitos de direito e de arte como

\footnotetext{
*Mestre em Gestão Pública pela Universidade Federal de Pernambuco, UFPE. Especialista em Gestão Pública pelo Instituto Federal de Pernambuco, IFPE. Licenciado em História pela Universidade Federal de Pernambuco, UFPE. Graduando em Direito. Endereço postal: UFRPE, Rua Dom Manuel de Medeiros, s/n - Dois Irmãos, Recife - PE, 52171-900. Endereço eletrônico: thiago.florentino@ufrpe.br.

*** Mestra em Gestão Pública pela Universidade Federal de Pernambuco, UFPE. Especialista em Gestão Pública pelo Instituto Federal de Pernambuco, IFPE. Bacharela em Geografia pela Universidade Federal de Pernambuco, UFPE. Graduanda em Direito. Endereço postal: UFRPE, Rua Dom Manuel de Medeiros, s/n - Dois Irmãos, Recife - PE, 52171-900. Endereço eletrônico: sandra.campos@ ufrpe.br.
} 
abertos. Decorrendo a conformidade com o estudo em teoria estética desenvolvido por Morris Weitz.

Fruto do gênio grego o conceito de devir tem como ponto central a dinamicidade que compõe a realidade de modo a demonstrar que o homem está inserido numa dinâmica de movimento e continuidade. Neste sentido, podemos relacionar esta dinâmica ao estudo das realidades jurídica e artística. Quanto à primeira, em razão de sua Teoria tridimensional do direito, diz Miguel Reale (1994, p. 79-80, grifo do autor),

o homem, na raiz de seu ser histórico, é enquanto deve ser, mas jamais a sua existência esgota as virtualidades de seu projetar-se temporal-axiológico, nem os valores são concebíveis extrapolados ou abstraídos do existir histórico.

Do mesmo modo o devir é evidenciado na acepção de arte de Ernst H. J. Gombrich (1999, p. 15, tradução nossa) ao enfatizar que "não existe, realmente, a Arte. Existem somente artistas". Assim, as perspectivas de Reale e Gombrich explanam o caráter dinâmico da existência humana, contanto que levemos em conta a importância das instituições, bem como de sua relação com o novo, por fim o simbólico.

No segundo tópico, demonstraremos a relação entre o devir e a definição dos conceitos em abertos e fechados. Abordando acerca da relação entre movimento e continuidade que denota que ser consiste em vir-a-ser. Vinculando o movimento/continuidade à teoria estética trazida no estudo de Morris Weitz. Além de apontamentos de Immanuel Kant (2001), George Dickie (2009) com sua Teoria institucional da arte e Clifford Geertz (1994) mediante a observância na simplificação do fato pela linguagem jurídica.

Subsequentemente, o terceiro tópico trata sobre a produção da ordem por meio da relação entre as instituições, retórica e verdade. Onde se demonstra que o movimento e continuidade têm uma relação numa mesma conjunção. Que se manifesta num continuum devido à mudança ser contínua e causa/conseqüência de uma ordem. O que é exemplificado através da obra de Marcel Duchamp, bem como por Antoine Garapon (1997) e Hans Blumenberg $(2001 ; 2013 ; 2018)$. Finalizando com o destaque da ordem na relação do direito e da arte com o contexto.

O último tópico traz a distinção entre a finitude humana e o institucionalizado de modo que desta diferença é expressa a ordem. Uma vez que a vinculação entre dado contexto e o consenso hegemônico, produzido institucionalmente, remete a relação entre a arte e o direito. Por meio da intervenção artística de Pierre Pinoncelli demonstraremos que a produção de um padrão de realidade termina por coadunar com o continuum estabelecido pelo devir. 
Para a efetivação deste artigo, aplicamos a pesquisa em literatura especializada, subsidiando a base teórica, seguindo uma investigação explicativa. Assim, o presente artigo tem sua relevância científica, e espera-se que sua leitura permita suscitar futuras pesquisas acerca dos assuntos abordados.

\title{
2. A RELAÇÃO ENTRE O DEVIR E A DEFINIÇÃO DOS CONCEITOS EM ABERTOS E FECHADOS
}

O longevo conceito de devir remonta aos filósofos pré-socráticos da escola de Mileto, século VI a.C. Inicialmente fora baseado na teorização do dinamismo universal, isto é, que tudo nasce, cresce e morre, entretanto, ele é efetivamente desenvolvido com a doutrina de Heráclito de Éfeso. Uma vez que este afirma que tal dinamicidade compõe a realidade nas dimensões, social, política e religiosa (REALE; ANTISERI, 2007, p. 23). Para Heráclito

\begin{abstract}
'não se pode descer duas vezes no mesmo rio e não se pode tocar duas vezes uma substância mortal no mesmo estado, pois, por causa da impetuosidade e da velocidade da mudança, ela se dispersa e se reúne, vem e vai. (...) Nós descemos e não descemos pelo mesmo rio, nós próprios somos e não somos' (HERÁCLITO apud REALE; ANTISERI, 2007, p. 22).
\end{abstract}

Assim, a relação entre movimento (descer e não descer, ser e não ser) e continuidade (a mudança é contínua) demonstra que ser é vir-a-ser. Que por sua vez é contraposta às características da filosofia de Parmênides, já que justificava a existência de uma essência imutável relacionada a uma verdade que terminaria negando a mudança na realidade ${ }^{1}$. Assim, uma verdade transcendental se opõe à mutabilidade que é central para a doutrina de Heráclito, posto que tudo escorre (panta rhei). Entretanto, a contínua mutabilidade, logo da passagem de um estado a outro não significa o caos. Pois, a contradição que remete ao fundamento do próprio devir estabelece um continuum plausível diante de uma "harmonia dos contrários". Ou seja, "destes contrários, diz Heráclito, nasce uma harmonia e, portanto, maravilhosa síntese unitária" (REALE; ANTISERI, 2007, p. 52).

Podemos vincular o movimento/continuidade à teoria estética mediante o estudo de Morris Weitz, O papel da teoria na estética (1954), em razão da reflexão da impossibilidade

\footnotetext{
${ }^{1}$ Ressaltamos que é válido o expresso por Giovanni Casertano sobre a necessidade em se "historicizar" a filosofia de Parmênides. Pois as características aqui utilizadas foram construídas ao longo da história da filosofia, ou ainda: "Sobre os grandes filósofos existem, com frequência, lendas que são transmitidas através dos séculos; não somente as lendas que acompanham a sua vida e seus episódios, mas também as que fixam as coordenadas do seu pensamento e da sua reflexão teórica" (CASERTANO, 2007, p. 308).
} 
de conceituar a arte nos termos "clássicos". Ou melhor, da impossibilidade de, mediante o exercício teórico, criar uma formulação final sobre a natureza da arte. Isto, em razão de que

a teoria estética - toda ela - está errada em princípio por pensar que uma teoria correta é possível, porque drasticamente interpreta mal a lógica do conceito de arte (WEITZ, 1954, p. 28, tradução nossa).

Portanto, com a intenção de compreender adequadamente a lógica deste conceito, Weitz, baseado na filosofia do segundo Wittgenstein, diferencia os conceitos em duas espécies: abertos e fechados. Os primeiros supõem que "as condições da sua aplicação são modificáveis e corrigíveis", já os fechados pressupõem que as "condições necessárias e suficientes para a aplicação de um conceito possam ser estabelecidas" (WEITZ, 1954, p. 31, tradução nossa). Neste sentido, em razão do conceito de arte ser aberto, é impossível uma conceituação teórica baseada "no requisito do senso clássico", ao tratar aquele como um conceito fechado, definitivo. ${ }^{2}$

Tal diferenciação já se encontrava nas observações de Immanuel Kant, Crítica da Razão Pura (1781), ao versar acerca do uso da razão pura nos conhecimentos filosóficos e matemáticos. Uma vez que o conhecimento filosófico "é o conhecimento racional por conceitos, o conhecimento matemático, por construção de conceitos" (A 713 / B 741) (KANT, 2001, p. 592). A partir disto, Kant alude que a construção dos conceitos matemáticos é possibilitada por uma existência prévia, a priori, de uma definição que possui clareza, limite e precisão. Contrariamente, os conceitos filosóficos possuem definições "defeituosas", por não possuírem esses três elementos. Isto, porque os conceitos filosóficos são empíricos, ou seja, vinculados à percepção e deste modo, à subjetividade.

Em vista disso, os conceitos vinculados à percepção não oferecem a segurança da inalterabilidade. De forma que este tipo de conceito "não pode ser definido, mas apenas explicitado" (A 727 B 755) (KANT, 2001, p. 601). Portanto, é compreensível o asseverado por Kant (A 731 B 759) (2001, p. 603): "em filosofia a definição, como clareza apropriada, deve antes terminar do que iniciar a obra". Pois, com o tempo a definição dos conceitos

\footnotetext{
${ }^{2}$ Alguns trabalhos são contrários ao posicionamento de Weitz. Aqui evidenciamos o artigo de Rosi Leny Morokawa intitulado: Definir ou não definir arte: objeções à tese da impossibilidade da definição de arte e perspectivas teóricas após Morris Weitz. Uma vez que similarmente a Giovanni Casertano é evidenciada a necessidade em se historicizar. Neste caso diz a autora "A abordagem de Weitz surge em um momento de incertezas no campo da teorização sobre arte. Se pensarmos na diversidade de obras de arte do período contemporâneo ao filósofo, podemos entender que as grandes teorias não davam mais conta de responder à extensão do que chamamos 'arte' ou 'obras de arte'. Diante dos novos casos de arte, pareceu difícil encontrar uma propriedade comum a todos eles" (MOROKAWA, 2018, p. 94). Para a superação do alertado, neste trabalho vincularemos a teoria de Weitz ao vir-a-ser, o repositório do novo.
} 
empíricos, mediante o consenso vão se aperfeiçoando. Contudo, não significa dizer que estes serão definidos como os conceitos matemáticos, já que em razão da subjetividade este tipo de conceito "nunca se mantém entre limites seguros". Algo que ocorre mesmo que os conceitos ligados à subjetividade sejam, a priori, como por exemplo, os conceitos de "substância, causa, direito, equidade" (A 728 B 756) (KANT, 2001, p. 601).

Justamente é a segurança proporcionada pelos conceitos "fechados" da arte que os teóricos da estética buscam. Como faz George Dickie em sua "Teoria institucional da arte", ao tentar fazer um "enquadramento essencial da arte" através do questionamento da "natureza institucional da arte" (DICKIE, 2009, p. 145). Afirmamos isto, em virtude de que tal busca termina por tomar uma "narrativa da arte" (DANTO, 2006) como sinônimo de uma verdade, permitindo um conceito fechado de arte. Logo, conceitos empíricos, vinculados a subjetividade, mediante o procedimento processualista da Teoria institucional da arte são simplificados. Ou seja, ao elencar critérios que uma vez preenchidos definem o fenômeno, é uma forma de simplificação deste fenômeno. Não tomamos isto como pejorativo, menor, mas como algo necessário a construção do consenso. O que, por sua vez, podemos interligar ao exposto pelo antropólogo Clifford Geertz (1994) quanto à necessidade da simplificação do fato pela linguagem jurídica. Ou seja, um conflito pode ser interpretado por múltiplas possibilidades, gerando a dúvida sobre quem possui a verdade. Mas, o direito a fim de dar uma resposta, necessita que o fato seja simplificado. E por relacionar uma linguagem abstrata a uma linguagem decisória, por meio da esterilização do fato, urge a necessidade de tal simplificação (GEERTZ, 1994, p. 210).

A simplificação que possibilita o discurso da feitura da justiça pelas técnicas do direito, não fornece para a Teoria estética a mesma segurança que um conceito matemático fechado. Uma vez que devido à fluidez contextual deveriam ser aplicados os conceitos "filosóficos empíricos" ou "abertos", propensos a reformulação. O que de certa forma é percebido pelo próprio George Dickie na reformulação de sua teoria:

Considero hoje que a versão da teoria institucional da arte que foi sendo trabalhada ao longo de uma série de anos, e que foi apresentada de forma mais completa nos capítulos I e VII de Art and the Aesthetic, se encontra errada em muitos dos seus pormenores. [...] Estou consciente da impossibilidade virtual de provar uma tese filosófica positiva que não se encontra trabalhada em detalhe (DICKIE, 2009, p. 111, grifo nosso).

Justamente a estes pormenores Kant nos chama a atenção por comporem a definição dos conceitos matemáticos, ou seja, a clareza, limite e precisão. De forma que "definir não 
deve significar propriamente, mais do que apresentar originariamente o conceito pormenorizado de uma coisa dentro dos seus limites" (A 727 B 755) (KANT, 2001, p. 601). Neste sentido e sobre o conceito de arte Adorno em seu Teoria Estética expõe que

como outros constituintes pelos quais a arte se tornou o que é, o seu cerne temporal exterioriza-se e faz explodir o seu conceito [...] A obra de arte é processo essencialmente na relação do todo com as partes. Não podendo reduzir-se nem a um nem a outro momento, esta relação é, por seu turno, um devir (ADORNO, 2008, p. 270).

Consequentemente é o devir ou movimento/continuidade que "faz explodir" o conceito, pois diante do tempo a perenidade do campo conceitual é extrapolada. O tempo emerge como crucial dada à centralidade da conjuntura sociocultural na escolha dentre o possível. O direito tem em seu ritual judiciário o meio de estabilização da relação entre as partes e o todo. Em seu Bem julgar: ensaio sobre o ritual judiciário, Antoine Garapon expressa isto ao dizer que

O ritual permite que os dois discursos sejam, ao mesmo tempo, contraditórios e legítimos. Autoriza uma diferenciação interna no direito e introduz a tensão sem ameaçar a sua unidade. Assim sendo, a violência do conflito, expressa por discursos opostos, mas controlada pelo conjunto do ritual, deixa de constituir uma ameaça [...] (GARAPON, 1997, p. 93, grifo nosso).

Logo, a extrapolação conceitual ocorrida, no seio do direito, tem em seu ritual a ligadura que permite a adequação entre as partes e o todo. Que possibilita a inserção da tensão sem a atemorização vinda da mutabilidade contextual. $O$ que não significa dizer que o conceito do direito adquire a segurança da definição imutável alcançada pelos conceitos matemáticos. Como no caso da percepção de George Dickie quanto aos erros nos pormenores de sua Teoria institucional da arte. Uma vez que, estes conceitos são construídos sobre bases "sólidas", ou seja, são baseados "em definições, axiomas e demonstrações" (A 727 B 755) (KANT, 2001, p. 600), o que impossibilita seu uso dentro dos conceitos sujeitos à experiência, a subjetividade. Sintetizando isto, Kant nos traz que

na matemática a definição pertence ad esse; na filosofia, ad melius esse. É belo, mas por vezes muito difícil, chegar a isto. Os juristas procuram ainda uma definição para o seu conceito de direito (A 731 B 759) (KANT, 2001, p. 603).

Assim, colocar o conceito aberto de arte ou direito sob os requisitos dos conceitos fechados é requerer que diante da busca por segurança e sob a égide da verdade imutável ambos subjazam. Contudo, é importante que se vincule esta necessidade de segurança à necessidade da produção consensual, pois há uma função instrumental para tal busca. Já que esta verdade igualmente é crucial na produção de um consenso. Onde definir a arte ou o 
direito através de conceitos fechados, definidos e estáveis, é um instrumento retórico. O que coaduna com o asseverado por Ernst H. J. Gombrich ao enfatizar que

não existe, realmente, a Arte. Existem somente artistas. [...] tal palavra pode significar muitas coisas distintas, em épocas e lugares diferentes e advertimos que a Arte, escrita com A maiúsculo, não existe, pois a Arte com A maiúsculo tem por essência ser um fantasma e um Ídolo (GOMBRICH, 1999, p. 15, tradução nossa).

Neste cenário o contexto é fruto da mudança/continuidade e condição dos conceitos abertos. Marcel Duchamp (2013) já afirmava que "uma obra de arte, vive e morre assim como nós". Não tomamos esta morte apenas como finitude, mas igualmente como continuidade. Pois não nos esqueçamos da "harmonia dos contrários" uma vez que o devir estabelece um continuum e este, em virtude da temporalidade, é conexo as instituições e assim a produção consensual.

\section{A ORDEM: O INSTITUCIONALIZADO ENTRE RETÓRICA E VERDADE}

Como visto a relação entre movimento e continuidade não é evidenciada fora de sua conjuntura. Pois, a mudança não representa um quadro caótico, mas apresenta uma regularidade, uma ordem. Ordem que não aprisiona, mas que compõe a própria mudança, por ser laço legitimador do futuro. De forma que esta legitimação se baseia na obtenção do consenso diante das possibilidades eclipsadas pelo discurso hegemônico.

O vínculo entre consenso e contexto é um possível desdobramento que pode ser suscitado. A indagação sobre o que é a arte pode nos demonstrar isto e de forma mais específica por meio da obra de Marcel Duchamp, Fountain (Fonte), consequentemente em meio às vanguardas artísticas européias. Em plena Primeira Guerra Mundial, 1917, ocorreu na cidade de Nova York a mostra de arte promovida pela Associação de Artistas Independentes que tinha o objetivo de promover a diversidade artística. Um dos idealizadores, Marcel Duchamp, sob o pseudônimo R. Mutt enviou um mictório de louça, cujo diferencial era a assinatura do artista.

A Fountain foi produzida baseada no conceito, formulado por Duchamp, de readymade, que consistia em assinar um objeto comum produzido em escala industrial, resultando na impossibilidade da definição do que é a arte (GIRST, 2014, p. 161). Após certa resistência, a Fountain é aceita e exposta de forma que, conforme Duchamp, "foi colocada atrás de uma divisória e, durante a exibição, eu não sabia onde estava" (CABANNE, 2009, p. 55, tradução 
nossa). Fato que estimulou a poetisa Louise Varèse a escrever ao jornal dada The Blind Man: "foi uma triste surpresa saber de um Conselho de Censores sobre a questão ambígua: o que é ARTE?" (BLIND MAN, 1917, p. 6, tradução nossa). Neste episódio, nos é apresentado sob a forma da ready-made, o questionamento sobre o que é a arte, bem como, se torna visível uma ordem diante da relutância na aprovação da Fountain, enquanto obra de arte a ser exibida. Ordem atrelada a um consenso contestado por Louise Varèse.

A relação entre consenso, ordem e arte pode ser exemplificada no estudo de Jaś Elsner (2012), sobre a iconoclastia como discurso. Neste estudo, foi identificado que as teorias de Platão e Aristóteles subsidiaram o pensamento iconoclasta dos períodos Helênico e Romano chegando aos "pais da Igreja". (ELSNER, 2012, p. 369). Neste sentido, igualmente Ernst Gombrich em seu Imagens Simbólicas alude que

o cristianismo herdou do platonismo um argumento essencial para a justificação do
simbolismo: chamado de doutrina dos dois mundos. Nosso mundo, o mundo dos
sentidos tal como conhecemos, não é de acordo com esta interpretação mais do que
um reflexo imperfeito do mundo inteligível, o mundo do espírito (GOMBRICH,
1986, p. 234, tradução nossa).

Deste modo, a expressão de uma verdade supra-sensível é manifesta na destruição de imagens religiosas, obras de arte e monumentos. Pois, a arte é tida como uma imitação da natureza, que por sua vez é apenas aparência da verdade inacessível em vida. Diante disto, é demonstrado que o vínculo entre a produção do consenso e a regularidade/ordem, perpassa as instituições. Em virtude da limitação temporal humana o consenso é institucionalizado ganhando sobrevida para além da finitude. Esta que se expressa no direito através da relação entre o ritual jurídico e o processo judicial.

Tal como qualquer ritual, o processo inverte o curso do tempo luta assim contra a finitude devido à sua capacidade para produzir um tempo original, isto é, um tempo que ainda não foi esbatido pelos anos, um tempo indeterminado o tempo original é o tempo da criação (GARAPON, 1997, p. 63).

Este tempo da criação se associa à própria necessidade da obtenção do consenso da legitimação pelo processo e rito. Ordem e consenso se vinculam ao tempo, pois sobre a terra firme são erguidas as instituições. Contudo a finitude também se apresenta sobre a posse da verdade, enquanto recurso na obtenção do consenso. E assim, as possibilidades relacionadas aos padrões institucionais se apresentam visíveis, de modo que são consideradas as melhores ou mesmo são apresentadas como as únicas possíveis.

Diante disto, a verdade na retórica, conforme Hans Blumenberg (2018, p. 278), assume duas "concepções básicas tradicionais". Uma vinculada a Aristóteles que liga a 
retórica às consequências da posse da verdade, de modo a torná-la mais evidente e atrativa. E outra atrelada à sofística que remonta a impossibilidade de se chegar à verdade. A importância disto reside que deste estudo sobre retórica e verdade se chega também às vertentes antropológicas que definem o homem como animal pobre ou rico. Ou seja, tais "alternativas radicais" de definição da retórica igualmente convergem para o estudo das posições divergentes da antropologia.

E assim, enquanto "criatura rica, o homem dispõe de sua posse da verdade com os meios eficazes do ornatus retórico. Como criatura pobre, o homem precisa da retórica como arte da aparência" (BLUMENBERG, 2018, p. 279). ${ }^{3}$ Aparência que torna possível o vislumbre da adoção da arte como Arte, logo a que "tem por essência ser um fantasma e um Ídolo", como nos aponta Gombrich (1999, p. 15, tradução nossa). Bem como, da contínua busca pelo conceito de direito, como apontado por Kant, de modo que este termine por ter uma "essência", tal qual a Arte, vinculada a um consenso retórico. Ao passo que do homem institucionalizado pelo Direito de "sua boca sairá um discurso convencionalmente tido como verdadeiro. À vestimenta institucional corresponde a verdade institucional” (GARAPON, 1997, p. 63). Contudo, em face da subjetividade o tipo de conceito ligado a Arte e Direito "nunca se mantém entre limites seguros" (A 728 B 756) (KANT, 2001, p. 601). O que se reflete nos reiterados rompimentos destes conceitos, uma vez que

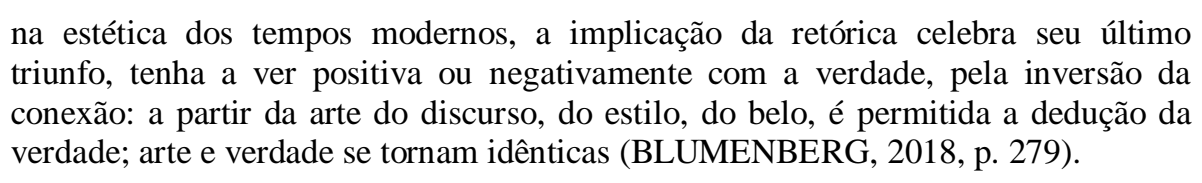

Logo, uma vinculação entre a estética moderna, verdade e retórica é estabelecida diante de uma nova feição assumida pelo capital e assim pelo contexto da modernidade. Uma forma artística que perpetra "hibridizações de todo tipo em que se cruzam a indústria, o comércio, a arte, a moda, o design, a publicidade" (LIPOVETSKY, 2015, p. 134). Onde o novo/imprevisível ligado às técnicas e estética modernas é agente da verdade, o que igualmente atinge o direito.

\footnotetext{
${ }^{3}$ Sobre isto assegura João Maurício Leitão Adeodato (2002, p. 81): "Na linha de Arnold Gehlen, Hans Blumenberg resume em duas linhas opostas as bases antropológicas de urna evolução na concepção da teoria do conhecimento que pode ser detectada no ocidente, divisão que se pode fazer aqui corresponder à dicotomia essencialismo versus retórica, ou à dicotomia verdade versus conjetura." A vertente a qual Adeodato faz menção, a Antropologia Filosófica Alemã, é melhor explicada no artigo de Joachim Fischer intitulado Exploring the Core Identity of Philosophical Anthropology through the Works of Max Scheler, Helmuth Plessner, and Arnold Gehlen. Ou ainda em seu livro Philosophische Anthropologie: Eine Denkrichtung des 20. Jahrhunderts.
} 
Neste sentido, tomamos o compreendido por Geertz (1994, p. 195), de que o direito é um ofício que atua à luz do conhecimento local, daí sua relação com a cultura. Bem como, é uma linguagem que simplifica os fatos para torná-los cabíveis às abstrações construídas culturalmente. De forma que o direito propõe um mundo no qual tenham sentido suas descrições (GEERTZ, 1994, p. 202). O que é necessário em virtude do próprio processo legal derivar da união das "representações estruturais do direito (em caso de/então) com as representações diretas do direito (já que/portanto)" (GEERTZ, 1994, p. 210, tradução nossa). E assim, é compreensível quando Garapon (1997, p. 34) afirma que "o espaço judiciário é como que uma espécie de mundo temporário no centro do mundo habitual, especialmente construído com vista à função nele exercida". Tomamos tal temporalidade como referente à própria temporalidade da retórica, pois por tempo limitado "a retórica cria instituições onde faltam evidências" (BLUMENBERG, 2018, p. 283).

No contexto social "a falta da evidência" é a falta da segurança proveniente do conceito fechado, todavia esta falta é possível no conceito aberto. Quanto ao conceito de direito, ele possibilita a incorporação da tensão, vinda da mutabilidade contextual, por meio do ritual judiciário. O que se expressa em virtude de que "o Ritual judiciário, cuja função é anular o crime, não se limita a restabelecer a ordem antiga: ele regenera a ordem social e cria a ordem a partir da desordem" (GARAPON, 1997, p. 65). Logo, uma linguagem abstrata se relaciona com uma linguagem de decisão, mediante a esterilização do fato, ou melhor, mediante a recriação da "gênese da ordem". Assim, chegamos ao devir (movimento/continuidade) diante da "harmonia dos contrários" em face da abertura conceitual do direito por recriar o tempo original mediante o processo. Quanto a isto, em razão da realidade cultural, a Teoria tridimensional de Miguel Reale, percebe a norma jurídica para além do dever-ser desaguando no vir-a-ser:

o termo 'tridimensional' só pode ser compreendido rigorosamente como traduzindo
um processo dialético, no qual o elemento normativo integra em si e supera a
correlação fático-axiológica, podendo a norma, por sua vez, converter-se em fato,
em um ulterior momento do processo, mas somente com referência e em função de
uma nova integração normativa determinada por novas exigências axiológicas e
novas intercorrências fáticas (REALE, 1994, p. 77 ).

Assim, a esterilização do fato não leva a imobilidade, mas sim se mostra como requisito de dada ordem cultural, pois "a cultura é a regulamentação de uma Ordem. Ou pressupõe a regulamentação de uma Ordem" (WITTGENSTEIN apud SLOTERDIJK, 2012, p. 177, tradução nossa). O dever-ser se apresenta como um integrante da cultura de modo que 
permite a ordem. Não imobilizando a cultura, pois em razão do devir (vir-a-ser) existirão “renovadas tensões fático-axiológicas" (REALE, 1994, p. 61), logo a possibilitando. Também Friedrich Müller em sua Teoria Estruturante do Direito estabelece a relação entre o direito e seu contexto por meio de seu conceito de normatividade ao estabelecer que esta

\begin{abstract}
designa a qualidade dinâmica de uma norma assim compreendida, tanto de ordenar à realidade que lhe subjaz - normatividade concreta - quanto de ser condicionada e estruturada por essa realidade - normatividade materialmente determinada. Com isso a pergunta pela relação entre direito e realidade já está dinamizada no enfoque teórico e a concretização prática é concebida como processo real de decisão (MÜLLER, 2008, p. 15).
\end{abstract}

Quanto ao direito ou mesmo a arte, procede de suas relações com o contexto a visibilidade da ordem, bem como das suas substituições. O devir (movimento/continuidade) segue e a "harmonia dos contrários" fomenta camadas de ordem. Estas resultantes das "renovadas tensões" que como respostas aos problemas correntes podem suscitar demandas a serem respondidas num momento posterior.

\title{
4. SOBRE O PADRÃO DE REALIDADE E AS CAMADAS DE ORDEM
}

Da distinção entre finitude humana e o institucionalizado, igualmente se torna visível, o movimento/continuidade que "faz explodir" o conceito, dado que "nós próprios somos e não somos". Este não ser nos remete às possibilidades não escolhidas, subentendidas. De modo que o pintor Paul Klee (2013, p. 166, tradução nossa) afirmara: “a arte não reproduz o visível, mas o torna visível". O que se expressa pelas intervenções do artista performático Pierre Pinoncelli, sobre uma das cópias da Fountain, criadas pelo próprio Duchamp em 1964. De forma que venha possibilitar o entendimento da relação entre o tempo e a instituição.

Em 1993 ocorreu durante uma exposição à primeira intervenção de Pinoncelli, na qual ele urinou e posteriormente golpeou, com um martelo, a valiosa cópia. Indo posteriormente a julgamento sob a acusação de "degradação voluntária de um monumento ou objeto de utilidade pública" (PONS, 1996, tradução nossa). Onde ele, em sua defesa, justificou o ato como

um gesto artístico que Marcel Duchamp 'teria compreendido' ao primeiramente devolver a Fountain sua 'função originária' e depois golpear o 'simples objeto' que voltou a ser (GAMBONI, 2014, p. 370, tradução nossa).

Portanto, a intervenção de Pinoncelli tinha por intuito resgatar o conceito de readymade. Já que este foi institucionalizado e posto sob a ordem de um dado contexto, o museu. 
Conceito que propiciou que um mictório produzido em escala industrial terminasse por adquirir o status de "monumento" ou "objeto de utilidade pública". Contudo, o mais importante é perceber que, o veio discursivo duchampiano prevaleceu e a arte encontra uma nova definição, onde o artista pode se sobressair à obra artística, uma vez que este escolhe uma possibilidade dentre as infinitas. Posto que "ele a ESCOLHEU. Ele pegou um objeto ordinário da vida, colocou em um lugar em que sua significância útil desaparece sob um novo título e ponto de vista" (BLIND MAN, 1917, p. 5, tradução nossa, grifo do autor). Fazendo sentido à frase lacônica de Gombrich (1999, p. 15), "não existe, realmente, a Arte. Existem somente artistas".

Revela-se, portanto o poder da escolha, como também o vínculo entre a escolha do objeto, o contexto e a ordem que os perpassa. Algo próximo ao que Pierre Bourdieu disse na conversa com o artista Hans Haacke, sobre a escolha de Duchamp:

ele usou o museu como um contexto de descontextualização, se é que posso usar a expressão. Ou seja: Eu pego um mictório e, pelo próprio fato de colocá-lo em um museu, eu mudo sua natureza [...] (BOURDIEU; HAACKE, 1995, p. 96, tradução nossa).

Assim, é patente a importância da escolha de uma nova qualificação do objeto, como também da aplicação desta escolha ante o padrão institucional. Por motivo da invisibilidade das possibilidades afastadas por este padrão, ou ainda diante da possibilidade elegida pela ordem institucional. Neste sentido, se percebe a importância do ato de Pinoncelli ocorrer durante a exposição no museu. O que coloca a "morte do trabalho" artístico, ou seja, sua institucionalização em contato com o movimento/continuidade. Algo exemplificado pela perspectiva de Pinoncelli referente ao vandalismo e Arte, exposta após a sua segunda intervenção em 2006:

Eu nunca atacaria um Rembrandt ou um Van Gogh. Isso seria vandalismo. Eles representam um diferente ... tipo de arte mais tradicional. Mas também deve haver lugar para o tipo de arte de Duchamp. O verdadeiro espírito de Duchamp (LICHFIELD, 2006, tradução nossa).

À vista disso, assumimos o pressuposto que a institucionalização traduz a presença e ressignificação do trabalho artístico frente ao devir, pois a ordem é pressuposto do movimento/continuidade, do continuum. Mas este consenso não implica na supressão total das outras possibilidades, nem na supressão do consenso dominante anterior, como demarcado pelo respeito, expresso por Pinoncelli, às obras de "tipo mais tradicional". As ordens que permeiam o mesmo espaço são vinculadas aos conceitos instituídos em épocas diferentes. Algo que igualmente se aplica ao direito, uma vez que "o simbolismo judiciário foi 
buscar muito dos seus elementos à mitologia, à Bíblia, à história, entre outros domínios" (GARAPON, 1997, p. 27). A multiplicidade de ordenamentos que aparentam ser uma unidade é composta por conceitos e possibilidades elegidas dentre tantas que permanecem suspendidas. Em parte, é o asseverado por Walter Benjamin, sobre como a empatia com o vencedor se relaciona com o tempo e as instituições:

Todos os que até hoje venceram participam do cortejo triunfal, em que os dominadores de hoje espezinham os corpos dos que estão prostrados no chão. Os despojos são carregados no cortejo, como de praxe. Esses despojos são o que chamamos bens culturais (BENJAMIN, 1987, p. 225).

Consequentemente, o discurso da inexistência de outra possibilidade atende ao padrão institucional, porém os consensos, em princípio díspares, vão sendo aglutinados. De modo que, as camadas de ordens se assentam similarmente ao descrito por Benjamin. Todavia, como nos demonstra o caso Pinoncelli, com a institucionalização não se sucede a "morte do trabalho", do contrário, a obra artística é utilizada como mais um material para a fabricação de dada realidade.

Pois, o consenso institucional, seja na Arte ou Direito é produzido diante da negação, onde as normas que fomentam um "padrão de realidade [Realitätsnorm]" (BLUMENBERG, 2001, p. 7) estão imbricadas com as possibilidades visíveis. Nessa conformidade, o que é ou não real também muda, em razão do devir (movimento/continuidade), dado que "tão logo deixa de haver o que se tinha por 'real', as próprias substituições se tornam 'o real'" (BLUMENBERG, 2013, p. 32). ${ }^{4}$ O próprio plural de realidade não era vislumbrado até a modernidade, circunstância verificada, sobretudo, com a criação kantiana da palavra Weltanschauung (visão de mundo), pois assim se explica "porque o 'mundo', como um todo, não pode ser objeto de uma 'visão', exceto de uma perspectiva transcendente [...]" (KOERNER, 1998, p. 301, tradução nossa).

Diante da institucionalização, o valor de mercado que o artista possui se relaciona, conforme Alessia Zorloni (2013), com suas identidades histórica e estilística. A identidade histórica está relacionada à "legitimação obtida dentro do sistema de arte", já a estilística, se caracteriza quando o artista "evoca as características de seu trabalho na imaginação coletiva" (ZORLONI, 2013, p. 90, tradução nossa). Ressaltamos que também na identidade estilística

\footnotetext{
${ }^{4} \mathrm{O}$ mesmo texto também traduzido por Luiz Costa Lima e publicado posteriormente, consta: "Tão logo não há mais o que valia como 'real' as próprias substituições se convertem em 'o real'" (BLUMENBERG, 2018, p. 292).
} 
aparecem as escolhas institucionais. Visto que, o estilo que a princípio denota a subjetividade artística igualmente é "usado como um dispositivo de corte, como uma arma e como uma categoria autodefinidora" (GINZBURG, 1998, p. 27, tradução nossa). Portanto, mediante a união destas identidades, o artista se torna uma marca e nesta condição se vincula aos agentes que compõem o sistema econômico da arte contemporânea. Contudo, o mais importante é perceber que, o veio discursivo duchampiano prevaleceu e a arte encontra uma nova definição, onde o artista pode se sobressair à obra artística.

Assim, o tempo é essencial para a compreensão da função institucional, dado que é função do conceito delimitar as possibilidades. Não sendo o produto do acaso, que a Fountain se tornou um bezerro de ouro. Não em sentido de falsidade, mas no de representação de sua influência diante das identidades histórica e estilística de Duchamp. Portanto, podemos atrelar a Fountain ao que Pierre Bourdieu (2016, p. 47) denominou como "obra testemunho". Isto, por servir como referência para outras obras, seja nas diferenças ou semelhanças, seja de forma explicita ou implícita. Cabe lembrar que foi o bezerro de ouro bíblico uma resposta urgente ante um contexto de indeterminação. Afinal diante da incerteza do retorno do profeta Moisés, intermediador do povo e Deus, urge a necessidade da previsibilidade do cotidiano. A destruição dos mandamentos simboliza a relação do mal com a quebra da ordem precedente, mas é este mal indeterminado, o repositório do novo e assim, constituinte do devir. ${ }^{5}$

Neste cenário a identidade impõe um estilo e este governa o gosto. Assim, a história e o indivíduo são interligados pelo estilo, por intermédio da ideia de continuidade ligada ao progresso, o que Peter Gay apresenta ao expor que o estilo

é forma e conteúdo, entrelaçados na estrutura de toda arte e todo ofício - incluindo a história. [...] o modo está indissociavelmente ligado ao assunto; o estilo molda e por sua vez é moldado pelo conteúdo (GAY, 1988, p. 3, tradução nossa).

A vinculação entre a forma e conteúdo nos remete a impossibilidade da cisão entre a arte e o direito, uma vez que o rito judiciário e seus símbolos são fundamentais para a recriação da "gênese da ordem". Dois símbolos importantes daquele rito, a toga e a arquitetura dos Palácios da Justiça são generosos exemplos do elo entre a Arte e o Direito,

\footnotetext{
${ }^{5}$ Este exemplo é igualmente utilizado por Hobbes quanto à associação do novo à quebra da ordem e o cotidiano: "quando Moisés, que lhes havia confirmado sua vocação por meio de milagres, e pela maneira feliz como os tirou do Egito, se ausentou por apenas quarenta dias, se revoltaram contra o culto do verdadeiro Deus, que por ele lhes fora recomendado, e, estabelecendo como seu deus um bezerro de ouro, caíram na idolatria dos egípcios, dos quais tão pouco tempo antes haviam sido libertados. Mais ainda, depois que Moisés, Aarão e Josué, e a geração que tinha assistido às grandes obras de Deus em Israel morreram, surgiu uma outra geração que adorou a Baal. De modo que quando faltaram os milagres faltou também a fé" (HOBBES, 2003, p. 104).
} 
estes agora com letras maiúsculas, uma vez que forma e conteúdo se unem ao próprio devir. E após tal união adquirem a legitimidade vinda do rito, estilo e da verdade enquanto "ornatus retórico". De modo que como dissera Klee (2013, p. 166, tradução nossa) “a arte não reproduz o visível, mas o torna visível".

\section{CONCLUSÃO}

Constatamos que os conceitos de arte e direito são do tipo aberto, tomando-se como base o exposto por Morris Weitz e Immanuel Kant. Culminando com a vinculação entre este tipo conceitual ao devir.

Igualmente se verificou que a ordem não é constituída por uma única linha atrelada a um progresso histórico, mas sim a um universo de possíveis. Onde forma e conteúdo se atrelam às instituições de modo a garantirem um consenso dominante. $\mathrm{O}$ que por sua vez não significa a supressão total das possibilidades subtendidas, mas que as tensões oriundas do vira-ser podem ser administradas pelo direito mediante seu rito.

Conclui-se assim, que a simplificação do fato pela linguagem jurídica se atrela a necessidade da retórica diante da percepção antropológica que toma o homem como um animal pobre. Dependente da produção do consenso de modo que o simbólico, o rito e a arte conferem legitimidade ao fazer direito. O que permitirá atrelar os estudos do direito a Antropologia Filosófica Alemã, para tanto se faz mister um melhor aprofundamento teórico acerca deste entrelaçamento analisado.

\section{REFERÊECIAS:}

ADEODATO, João Maurício. Ética e retórica - para uma teoria da dogmática jurídica. São Paulo: Saraiva, 2002.

ADORNO, Theodor W.. Teoria Estética. Lisboa: Edições 70, 2008.

BENJAMIN, Walter. Sobre o conceito da história In: Magia e Técnica, Arte e Política. Ensaios Sobre Literatura e História da Cultura. Obras Escolhidas. Vol. 1. 3. ed. São Paulo, Brasiliense, p. 222-232, 1987.

BLUMENBERG, Hans. Ästhetische und metaphorologische Schriften. Frankfurt: Suhrkamp, 2001. 
Teoria da não conceitualidade. Belo Horizonte: Editora UFMG, 2013.

. Aproximação antropológica à atualidade da retórica. História da Historiografia , v. 26, p. 278-304, 2018.

BOURDIEU, Pierre. La distinción. Criterio y bases sociales del gusto. Madri: Editorial Taurus, 2016.

BOURDIEU, Pierre; HAACKE, Hans. Free Exchange. Cambridge: Polity, 1995.

CABANNE, Pierre. Dialogues With Marcel Duchamp. Boston: Da Capo Press, 2009.

CASERTANO, Giovanni. A cidade, o verdadeiro e o falso em Parmênides. Kriterion, Belo Horizonte, v. 48, n. 116, p. 307-327, dec. 2007. Disponível em: <http://dx.doi.org/10.1590/S0100-512X2007000200003>. Acesso: 13 ago. 2019.

DICKIE, George. A teoria institucional da arte. In: MOURA, Vítor (Org.). Arte em teoria, uma antologia de estética. Braga: Edições Húmus, p. 111-165, 2009.

DUCHAMP, Marcel. An interview with Marcel Duchamp. The Art Newspaper, Londres, 29 mar. 2013. Disponível em: <http://ec2-79-125-124-178.eu-west1.compute.amazonaws.com/articles/An-interview-with-Marcel-Duchamp/29278>. Acesso: 15 ago. 2019.

ELSNER, Jaś. Iconoclasm as Discourse: From Antiquity to Byzantium. The Art Bulletin, v. 94, n. 3, p. 368-394, Set. 2012. Disponível em: < https://doi.org/10.1080/00043079.2012.10786048>. Acesso: 12 ago. 2019.

GAMBONI, Dario. La destrucción del arte. Iconoclasia y vandalismo desde la Revolución Francesa. Madrid: Ediciones Cátedra, 2014.

GARAPON, Antoine. Bem julgar: ensaio sobre o ritual do Judiciário. Lisboa, Instituto Piaget, 1997.

GAY, Peter. Styles in History. 2. ed. New York: W.W. Norton and Company, 1988.

GEERTZ, Clifford. Conocimiento local: ensayos sobre la interpretación de las culturas. Barcelona; Bueno Aires; México: Paidós, 1994.

GINZBURG, Carlo. Style as Inclusion, Style as Exclusion. In: Caroline A. Jones e Peter Galison (Org.). Picturing Science, Producing Art. Londres/Nova York: Routledge, p. 27-54, 1998.

GIRST, Thomas. The Duchamp Dictionary. Londres: Thames \& Hudson, 2014.

GOMBRICH, Ernst Hans Josef. Imágenes simbólicas: Estudios sobre el arte del Renacimiento. 2. ed. Madri: Alianza, 1986. 
La Historia del arte. 16. ed. Cidade do México, CONACULTA; DIANA, 1999.

HOBBES, Thomas. Leviatã. Matéria, forma e poder de um Estado eclesiástico e civil. São Paulo: Martins Fontes, 2003.

KANT, Immanuel. Crítica da Razão Pura. 5. ed. Lisboa: Fundação Calouste Gulbenkian, 2001.

KLEE, Paul. Paul Klee. New York: Parkstone Press International, 2013.

KOERNER, Joseph Leo. Hieronymus Bosch's World Picture. In: Caroline A. Jones e Peter Galison (Org.). Picturing Science, Producing Art. Londres, Nova York: Routledge, p. 297323, 1998.

LICHFIELD, John. Pierre Pinoncelli: This man is not an artist. The Independent. Londres, 13 fev. 2006. Disponível em: <https://www.independent.co.uk/news/world/europe/pierrepinoncelli-this-man-is-not-an-artist-466430.html>. Acesso: 13 ago. 2019.

MOROKAWA, Rosi Leny. Definir ou não definir arte: objeções à tese da impossibilidade da definição de arte e perspectivas teóricas após Morris Weitz. ARS, São Paulo, v. 16, n. 34, p. 93-111, dec. 2018 Disponível em: <http://www.scielo.br/scielo.php?script=sci_arttext\&pid=S1678-

53202018000300093\&lng=en\&nrm=iso>. Acesso: 12 ago. 2019.

MÜLLER, Friedrich. Teoria Estruturante do Direito. São Paulo: Editora Revista dos Tribunais, 2008.

PONS, Anne. Pinoncelli, l'homme qui a pissé sur Duchamp. L'Express, 1996. Disponível em: $<$ https://www.lexpress.fr/informations/pinoncelli-l-homme-qui-a-pisse-surduchamp_617870.html >. Acesso em: 13 ago. 2019.

REALE, Giovanni; ANTISERI, Dario. História da filosofia: filosofia pagã antiga. 3. ed. Vol. 1 São Paulo: Paulus, 2007.

REALE, Miguel. Teoria tridimensional do direito. 5. ed. São Paulo: Saraiva, 1994.

SLOTERDIJK, Peter. Has de cambiar tu vida. Valencia: Pre-Textos, 2012.

THE BLIND MAN. Nova York, nº 2, mai. 1917.

WEITZ, Morris. The Role of Theory in Aesthetics. The Journal of Aesthetics and Art Criticism, v.15, n. 1, p. 27-35, set., 1956.

ZORLONI, Alessia. The Economics of Contemporary Art - Markets, Strategies and Stardom. Berlim: Springer, 2013. 